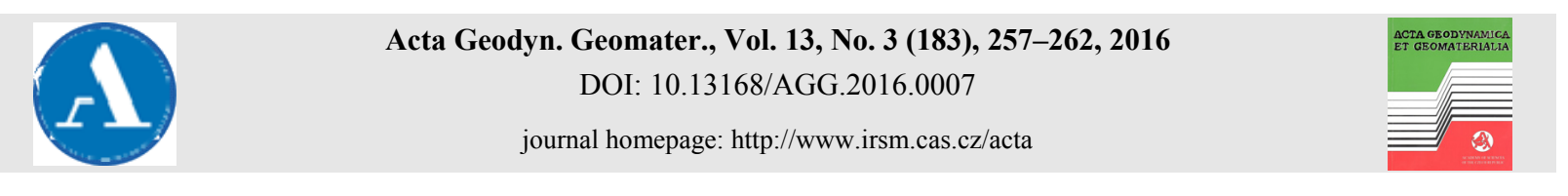

ORIGINAL PAPER

\title{
ANALYSIS OF IONOSPHERIC TEC VARIATIONS RESPONSE TO THE Mw 7.2 VAN EARTHQUAKE
}

\author{
Salih ALCAY
}

Necmettin Erbakan University, Engineering and Architecture Faculty, Geomatics Engineering Department, Konya-Turkey

*Corresponding author's e-mail: salcay@konya.edu.tr

\begin{tabular}{|c|c|}
\hline ARTICLE INFO & ABSTRACT \\
\hline Article history: & \multirow{6}{*}{$\begin{array}{l}\text { This paper investigates the pre-earthquake ionospheric variations using Total Electron Content } \\
\text { (TEC) of Precise Point Positioning (PPP) based regional ionospheric maps and Global } \\
\text { Ionospheric Maps (GIMs) during the } 7.2 \mathrm{Mw} \text { Van earthquake which occurred on October } 23 \text {, } \\
\text { 2011. TEC Maps around the epicenter from } 10 \text { days before to } 4 \text { days after the earthquake were } \\
\text { examined. In addition, time series of the TEC values were evaluated and results showed that the } \\
\text { ionospheric TEC was increased obviously } 3 \text { days before and } 2 \text { days after the earthquake. These } \\
\text { variations of the TEC were possibly associated with the seismic activity and geomagnetic storm } \\
\text { respectively. }\end{array}$} \\
\hline Received 01 December 2015 & \\
\hline Accepted 23 February 2016 & \\
\hline Available online 9 March 2016 & \\
\hline Keywords: & \\
\hline $\begin{array}{l}\text { Earthquake } \\
\text { Ionosphere }\end{array}$ & \\
\hline
\end{tabular}

Global Ionosphere Map (GIM)

Precise Point Positioning (PPP)

Seismo-Ionospheric Anomaly

Total Electron Content (TEC)

\section{INTRODUCTION}

Earthquake is one of the most destructive natural disasters that can cause many loss of human life. In order to promote the research on earthquake prediction, the study on the seismo-ionospheric anomaly has become a major topic for seismologists (Zhu et. al., 2014). Since the ionospheric variations may be caused by many factors such as geomagnetic storm or solar flares etc, it is necessary to distinguish ionospheric anomalies associated with earthquakes if they occur during the same time period. Relation between pre-earthquake ionospheric anomalies and earthquake was first studied by Leonard and Barnes (1965) for the Alaska earthquake, occurred in 1964. Many research verified that the ionospheric variation associated with seismic activity appearing prior to the event (Zhu et al., 2013; Zhou et al., 2009; Zhu et al., 2014; Afraimovich et al., 2004; Liperovsky et al., 2000; Liu et al., 2004; Karia et al., 2014; Kim et al., 2012; Zakharenkova et al., 2008; Yao et al., 2012; Trigunait et al., 2004; Pulinets et al., 2006). In order to analyze pre-earthquake ionospheric anomalies, ionosonde and Global Navigation Satellite System (GNSS) data have generally used in most researches. However there are less than 300 ionosondes available and only a fraction of them are continuously operational (Zhou et al., 2009). Therefore, recently GNSS Total Electron Content (TEC) observations derived by using dual frequency measurements are mostly used for continuously monitoring ionospheric changes.

Perevalova et al. (2014) investigated the ionospheric wave disturbances induced by earthqu- akes of different magnitude revealed no wave disturbances in TEC variations with magnitudes of 4.1-6.3. Responses to earthquakes with 6.5-6.7 were hard to distinguish at the level of background oscillations. In addition, TEC disturbances triggered by strong earthquakes with $7.2<\mathrm{Mw}<8.8$ were registered with confidence. However, Afraimovich et al. (2004) examined the TEC variations during the Mw 7.1 Hector Mine earthquake that occurred in 1999, California. Analysis showed that the observed VTEC variations seem to have been controlled by the local time and by fairly moderate geomagnetic activity instead of being associated with any expected process that usually accompanies the process of earthquake preparation. Zhu et al. (2014) conducted a statistical study on the temporal distribution of the GPS TEC anomalies prior to the earthquakes with magnitude $M \geq 7.0$ in the global area during 2003-2012 by the method of statistical analysis. According to the analysis, it was observed that the ionospheric negative anomalies mainly occur in one week prior to the earthquakes. Liu et al. (2004) investigated the abnormal signal during all of the $20 \mathrm{M} \geq 6.0$ earthquakes in the Taiwan area from September 1999 to December 2002. Results showed that the preearthquake ionospheric anomalies appeared within 5 days prior to 16 of the $20 \mathrm{M} \geq 6.0$ earthquakes. Besides, Karia and Pathak (2011) presented the analysis of GPS based TEC corresponding to eleven earthquakes $(M \geq 5.0)$ during the year 2009 in India and neighbouring regions. By looking into the features on temporal enhancement and depletion of TEC a prediction was made 3-2 days prior to the 
earthquakes. Zakharenkova et al. (2006) examined the ionospheric effects of the Indonesian earthquake using Global TEC Maps. 2 days prior to the event a positive effect was observed.

Zolotov et al. (2013) examined the October 23, 2011 Van earthquake. During 20-23 October 2011, particularly 21 October 2011, ionospheric disturbances were detected. Unlike this study, in the present study besides GIMs, regional ionospheric maps, associated with PPP technique was applied. In addition, time series of the TEC values were also examined. Although 21 October is one of the disturbed day, anomaly level reaching highest level on October 20 according to the statistical analysis. In addition Arikan et al. (2012), used symmetric Kullback-Leibler divergence (SKLD) to detect TEC variability prior to the October 23, 2011 Van earthquake. They detected significant TEC variation eight and nine days prior to the event. This variation also determined in the time series of the present study however it is below the upper bound. In addition preearthquake ionospheric anomaly is mostly detected within a week prior to the earthquake. The present study focused on ionospheric TEC variations prior to the earthquake and physical mechanism of the preearthquake anomaly was not taken into account.

\section{THE VAN EARTHQUAKE}

A strong earthquake of magnitude 7.2 occurred on 23 October 2011 near the VAN city in Turkey (Fig. 1). It was the largest earthquake in Turkey after 1999, Golcuk and Duzce earthquakes. It caused severe economic loss and many casualties. The event was occurred at 13:41 LT (10:41 UT) and epicenter position was $38.691^{\circ} \mathrm{N}$ and $43.497^{\circ} \mathrm{E}$. Yildırım et al. (2014) examined the influence of the earthquake geodetically. According to their analysis greatest variation was observed at Muradiye station which is closest to the epicenter of the earthquake. The variation in the station was $-42.7 \mathrm{~mm}$ in the vertical direction, $-60.3 \mathrm{~mm}$ in the northern direction and $18.7 \mathrm{~mm}$ in the eastern direction.

\section{THE GEOMAGNETIC AND SOLAR CONDITIONS}

Detection of seismo-ionospheric anomalies is complicated in periods of geomagnetic activity, when much stronger variations of the ionospheric parameters 'mask' weaker seismo-ionospheric variations (Zakharenkova et al., 2006). Figure 2 represents the variations of geomagnetic (Dst, Kp, ap) and solar activity index (F10.7) from 10 days before to 4 days after the earthquake (13-27 October 2011). Geomagnetic and solar activity index values were obtained from ISGI web site (http://isgi.latmos.ipsl.fr) and SEPC website

(http://engsepc.ac.cn/F107Index.php) respectively.

According to the index values, geomagnetic conditions were relatively quiet prior to the earthquake. $\mathrm{Kp}$ and ap indices did not exceed 4 quasilogarithmic scale (qls), 18 (2nT) respectively. In addition Dst values larger than -20 nanoteslas (nT).
However, solar activity index (F10.7) represented solar radiation prior to the earthquake. Particularly, 2 days prior to the event (October 21), solar activity index (F10.7) value reached 168 solar flux units (sfu) which signify the strongest solar radiation of the period. In addition, one can see that 2 days after the event, moderate geomagnetic storm occurred (Figure 2).

\section{DATA SOURCES}

For the analysis of seismo-ionospheric effects, the global VTEC, hereinafter referred to as TEC, maps in the IONEX format and PPP based regional TEC maps were used. IONEX data are accessible at the site: ftp://ftp.unibe.ch/aiub/CODE. The global TEC maps are generated by the IGS with a spatial resolution of $5^{\circ}$ longitude and $2.5^{\circ}$ latitude and a time interval of $2 \mathrm{~h}$.

Besides GIMs, PPP based regional maps were estimated using Bernese 5.0 GNSS software. PPP is a special case of zero-difference positioning which allows ionosphere model determination. Bernese Processing Engine (BPE) was used in this study. The used script, PPP ION, is responsible for ionosphere estimation. Regional ionosphere model was generated and stored in IONEX file format for the anomaly region. For the details author refer to Dach et al (2007). With a single station it is possible to observe certain part of the ionosphere. Dimension of this area can be determined by the "coverage circle" concept using following equations (Hugentobler et al., 2001).

$$
\begin{aligned}
& \sin z^{\prime}=\frac{R}{R+H} \sin z \\
& \tan \left(z-z^{\prime}\right)=\frac{r}{R+H}
\end{aligned}
$$

where $\mathrm{r}$ is the radius of the coverage circle, $z$ and $z$, denote zenith distances at the height of the station and single layer respectively. While $\mathrm{R}$ is the radius of the earth, $\mathrm{H}$ is height of the single layer above the earth surface. Choosing the $15^{\circ}$ cut off angle and $450 \mathrm{~km}$ single layer height, ionosphere can be observed nearly with a radius of $1270 \mathrm{~km}$ at each station. Therefore, TEC maps associated with the earthquake region were chosen for 20-36 latitude and 80-100 longitude. The regional TEC maps were generated with a resolution of $1^{\circ}$.

\section{STATISTICAL ANALYSIS AND \\ INTERPRETATION}

As previously applied in the description of TEC anomalies associated with earthquake (Zhu et al., 2013; Zhou et al., 2009), statistical analysis was used. Mean $\bar{x}$ of the previous 10 day TECs for the same time intervals and the associated standard deviation $\sigma$ to construct the upper bound $(\bar{x}+2 \sigma)$ and the lower bound $(\bar{x}-2 \sigma)$ were computed. If the TEC value at this time point falls out of either the associated lower bound or associated upper bound, then this time point is defined as a positive or negative anomaly with a confidence level of about $95 \%$ (Zhou et al., 2009; Zhu et al., 2013). 
For doing this, if the difference between the observed TEC and mean value, designed as $\triangle \mathrm{TEC}$, was less than twice the standard deviation, set to $\triangle \mathrm{TEC}=0 . \quad \triangle \mathrm{TEC}>0$ indicates positive anomaly; $\triangle \mathrm{TEC}<0$ indicates negative anomalies. Global $\triangle \mathrm{TEC}$ maps were investigated for this purpose and positive anomaly was detected 3 days prior to and 2 days after the earthquake. Figures 3-5 show the global $\triangle$ TEC maps corresponding to 3 days prior to the event (20.10.2011), from 8:00 UT to 12:00 UT, with a time interval of $2 \mathrm{~h}$.

It is possible to observe the ionospheric anomalies which began at 8:UT and close to the epicenter, depicting as a red dot in all the maps. The most affected area located roughly $85^{\circ} \mathrm{E}, 27^{\circ} \mathrm{N}$, with maximum $\triangle \mathrm{TEC}$ of 22 TECU at $10 \mathrm{UT}$. The anomalous gradually disappeared after 12 UT. There was no significant ionospheric anomaly in the rest of the world at this time. Besides, according to the indice values (Fig. 2), geomagnetic conditions were relatively quiet however solar radiations were detected prior to the earthquake and reached maximum level on October 21. The ionospheric anomalies caused by solar and magnetic field activities generally manifest over a wider geographic range (Yao et al., 2012). Such an example is given in Figure 6, which is related to the geomagnetic activity occurred 2 days after the Van earthquake.

The ionospheric anomalies observed on October 20, however appeared only near the epicenter. This provides evidence that the ionospheric anomalies on October 20 were associated with the proceeding earthquake.

Besides global $\triangle T E C$ maps, PPP based regional $\triangle T E C$ maps corresponding anomaly region were estimated using LHAZ IGS station which is close to this region. PPP based $\triangle T E C$ maps were chosen for 20-36 latitude and 80-100 longitude. Similar to the global $\triangle$ TEC maps positive anomaly was detected at 8 UT, 10 UT and 12 UT on 20 October 2011 (Figs. 7-9).

As is shown in Figures (7-9), similar to the GIMs maximum anomaly was appeared at $10 \mathrm{UT}$ and its effect decreased at 12 UT.

Besides $\triangle T E C$ maps, time series of the TEC values corresponding to epicenter of the anomaly region were excluded from PPP maps. Figures 10-11 demonstrate the time series of TECs, mean, upper and lower bounds.

From Figures 10-11 we can clearly see that TEC values started to increase 5 days prior to the earthquake and reached maximum value 3 days prior to the event. There were significant positive anomalies on October 20. It is beyond the upper bound. As presented above, this anomalous behavior of the TEC was related to the forthcoming earthquake with high probability. However 2 days after the event, occurred ionospheric response were caused by geomagnetic storm (see Fig. 2). In addition, TEC values of remaining days were generally close to the mean values.

Although the low solar and geomagnetic activity could not lead to the ionospheric anomalies during the seismic event, due to the thermospheric dynamics caused by various types of atmospheric disturbances the TEC may generate significant day to day variation even during magnetically quiet period (Zhou et al., 2009). However according to the previous background, TEC variation associated with thermospheric dynamics usually does not exceed $30 \%$ (Forbes et al., 2000; Rishbeth and Mendillo, 2001; Mendillo et al., 2002; Pulinets and Boyarchuk, 2004; Zhou et al., 2009). On October 20, the TEC variation went beyond the limit of $30 \%$ relative to the nondisturbed state.

\section{CONCLUSION}

Using the global and regional maps, ionospheric variations were observed before the Van earthquake. TEC values reached highest level (110 TECu) 3 days prior to the event. In addition, time series of the TEC values were also examined and positive anomaly was detected on 20 October 2011. This anomaly was more clear in PPP results. It was related to the earthquake with high probably. However TEC anomaly, two days after the event, was associated with the geomagnetic disturbances.

This study was only focused on the ionospheric TEC variations associated with seismo ionospheric activity. The detailed aspects of physical mechanism of the seismo ionospheric activity were already examined in many researches (Sorokin et al., 2001; Shinagawa et al., 2007; Liu et al., 2011; Zolotov et al., 2012).

Similar to the previous studies related to different earthquakes (Yao et al., 2012; Zhu et al., 2013; Karia and Pathak, 2011; Karia et al., 2014; Kim et al., 2012; He et al., 2012; Klinemko et al., 2011; Liu et al., 2004), this study confirmed the ionospheric anomalies occurring a few days prior to the earthquake. In addition this study also indicate that PPP based regional ionospheric maps are useful to examine ionospheric variations related to the earthquake.

\section{REFERENCES}

Aframovich, E.L., Astafieva, E.I., Gokhberg, M.B., Lapshin, V.M., Permyakova, V.E., Steblov, G.M. and Shalimov, S.L.: 2004, Variations of the total electron content in the ionosphere from GPS data recorded during the Hector Mine earthquake of October 16, 1999, California. Rus. J. Earth Sci., 6, No. 5, 339-354. DOI: 10.2205/2004ES000155

Arikan, F., Deviren, M.N., Lenk, O., Sezen, U. and Arikan, O.: 2012, Observed ionospheric effects of 23 October 2011 Van, Turkey earthquake. Geomatics, Natural Hazards and Risk, 3, No. 1, 1-8. DOI: 10.1080/19475705.2011.638027

Dach, R., Hugentobler, U., Fridezz, P. and Meindl, M.: 2007, User manuel of the Bernese GPS Software Version 5.0. Astronomical Institute, University of Bern.

Forbes, J.M., Palo, S.E. and Zhang, X.L.: 2000, Variability of the ionosphere. Journal of Atmospheric and SolarTerrestrial Physics, 62, 685-693. DOI: $10.1016 /$ S1364-6826(00)00029-8 
He, L., Wu, L., Pulinets, S., Liu, S. and Yang, F.: 2012, A nonlinear background removal method for seismoionospheric anomaly analysis under a complex solar activity scenario: A case study of the M 9.0 Tohoku earthquake. Advances in Space Research, 50, 211220. DOI: $10.1016 /$ j.asr.2012.04.001

Hugentobler, U., Schaer, S., Pridez, F., Beutler, G. and Bock, H.: 2001, Bernese GPS software version 4.2, Astronomical Institute University of Berne.

Karia, S.P. and Pathak, K.N: 2011, Change in refractivity of the atmosphere and large variation in TEC associated with some earthquakes, observed from GPS receiver. Advances in Space Research 47, 867-876. DOI: 10.1016/j.asr.2010.09.019

Karia, S.P., Pathak, K.N, Yadav, K.S, Chaudhary, N.P. Patel, N.C. and Jana, R.: 2014, Modification in atmospheric refractivity and GPS based TEC as earthquake precursors. Positioning, 5, 46-52. DOI: $10.4236 /$ pos.2014.52006

Kim, V.P., Liu, J.Y. and Hegal, V.V.: 2012, Modeling the pre-earthquake electrostatic effect on the $\mathrm{F}$ region ionosphere. Advances in Space Research, 50, 15241533. DOI: 10.1016/j.asr.2012.07.023

Klımenko, M.V., Klımenko, V.V., Zakharenkova, I.E., Pukınets, S.A., Zhao, B. and Tsidilına, M.N.: 2011, Formation mechanism of great positive TEC disturbances prior to Wenchuan earthquake on May 12, 2008. Adv. Space Res., 48, 488-499. DOI: 10.1016/j.asr.2011.03.040

Leonard, R.S. and Barnes, R.: 1965, Observation of ionospheric disturbances following the Alaska earthquake. J. Geophys. Res., 70, 1250-1253. DOI: 10.1029/JZ070i005p01250

Liperovsky, V.A., Pokhotelov, O.A., Liperovskaya, E.V., Parrot, M., Meister, C.V. and Alimov, O.A.: 2000, Modification of sporadic E-layers caused by seismic activity. Surv. Geophys., 21, 449-486. DOI: $10.1023 / \mathrm{A}: 1006711603561$

Liu, J.Y., Chuo, Y.J., Shan, S.J., Tsa1, Y.B., Chen, Y.I., Pulınets, S.A. and Yu, S.B.: 2004, Pre-earthquake ionospheric anomalies registered by continuous GPS TEC measurements. Annales Geophysicae, 22, No. 5,1585-1593. DOI: 10.5194/angeo-22-1585-2004

Liu, J.Y., Le, H., Chen, Y.I., Chen, C.H., Liu, L., Wan, W., Su, Y.Z., Sun, Y.Y., Lin, C.H. and Chen, M.Q.: 2011, Observations and simulations of seismoionospheric GPS total electron content anomalies before the 12 January 2010 M7 Haiti earthquake. J. Geophys. Res., 116, A04302. DOI: 10.1029/2010JA015704

Mendillo, M., Rishbeth, H., Roble, R.G. and Wroten, J: 2002, Modelling F2-layer seasonal trends and day-today variability driven by coupling with the lower atmosphere. Journal of Atmospheric and SolarTerrestrial Physics, 64, 1911-1931. DOI: $10.1016 / \mathrm{S} 1364-6826(02) 00193-1$

Perevalova, N.P., Sankov, V.A., Astafyeva, E.I. and Zhupityaeva, A.S.: 2014. Threshold magnitude for Ionospheric TEC response to earthquakes. J. Atmos. Sol.-Terr. Phys. 108, 77-90. DOI: 10.1016/j.jastp.2013.12.014

Pulinets, S.A. and Boyarchuk, K.: 2004, Ionospheric Precursors of Earthquakes. Springer, Berlin, Germany, $315 \mathrm{pp}$.

Pulinets, S.A., Ouzounov, D., Ciraolo, L., Singh, R., Cervone, G., Leyva, A., Dunajecka, M., Karelin, A.V., Boyarchuk, K.A. and Kotsarenko, A.: 2006, Thermal, atmospheric and ionospheric anomalies around the time of the Colima M7.8 earthquake of 21 January 2003. Annales Geophysicae, 24, 835-849. DOI: $10.5194 /$ angeo-24-835-2006
Rishbeth, H. and Mendillo, M.: 2001, Patterns of F2-layer variability. Journal of Atmospheric and SolarTerrestrial Physics, 63, 1661-1680. DOI: $10.1016 / \mathrm{S} 1364-6826(01) 00036-0$

Shinagawa, H., Iyemori, T., Saito, S. and Maruyama, T., 2007, A numerical simulation of ionospheric and atmospheric variations associated with the Sumatra earthquake on December 26, 2004. Earth Planets Space, 59, 1015-1026. DOI: 10.1186/BF03352042

Sorokin, V.M., Chmyrev, V.M. and Yashchenko, A.K.: 2001, Electrodynamic model of the lower atmosphere and the ionosphere coupling. Journal of Atmospheric and Solar-Terrestrial Physics, 63, 1681-1691. DOI: $10.1016 / \mathrm{S} 1364-6826(01) 00047-5$

Trigunait, A., Parrot, M., Pulinets, S. and Li, F. : 2004, Variations of the ionospheric electron density during the Buhj seismic event. Annales Geophysicae, 22, 4123-4131. DOI: 10.5194/angeo-22-4123-2004.

Yao, Y.B., Chen, P., Wu, H., Zhang, S. and Peng, W.F.: 2012, Analysis of ionospheric anomalies before the $2011 \mathrm{Mw}$ 9.0 Japan earthquake. Chin. Sci. Bull., 57, 500-510. DOI: 10.1007/s11434-011-4851-y

Yildirim, O., Yaprak, S. and Inal, C.: 2014, Determination of 2011 Van/Turkey earthquake $(M=7.2)$ effects from measurements of CORS-TR network. Geomatics Natural Hazards and Risk, 5, 2, 132-144. DOI: 10.1080/19475705.2013.789453

Zakharenkova, I.E., Krankowski, A. and Shagimuratov, I.I.: 2006, Modification of the low-latitude ionosphere before the 26 December 2004 Indonesian earthquake. Nat. Hazards Earth Syst. Sci., 6, 817-823. DOI: $10.5194 /$ nhess/-6-817-2006

Zakharenkova, I.E., Shagimuratov, I.I., Tepenitzina, N.YU.A. and Krankowski, A.: 2008, Anomalous modification of the ionospheric total electron content prior to the 26 September 2005 Peru earthquake. J. Atmos. Sol.-Terr. Phys., 70, 1919-1928.

DOI: 10.1016/j.jastp.2008.06.003

Zhou, Y., Wu, Y., Qiao, X. and Zhang, X. : 2009, Ionospheric anomalies detected by ground-based GPS before the Mw7.9 Wenchuan earthquake of May 12, 2008, China. Journal of Atmospheric and Solar Terrestrial Physics, 71, 959-966. DOI: $10.1016 /$ j.jastp.2009.03.024

Zhu, F., Zhou, Y., Lin, J. and Fu, F.: 2014, A statistical study on the temporal distribution of ionospheric TEC anomalies prior to M7.0+ earthquakes during 20032012. Astrophys Space Sci., 350, 449-457. DOI: 10.1007/s10509-014-1777-2

Zhu, F., Zhou, Y. and Wu, Y.: Anamolous variation in GPS TEC prior to the 11 April 2012 Sumatra earthquake. Astrophys Space Sci., 345, 231-237. DOI: $10.1007 / \mathrm{s} 10509-013-1389-2$

Zolotov, O.V., Namgaladze, A.A., Zakharenkova, I.E., Martynenko, O.V. and Shagimuratov, I.I.: 2012, Physical interpretation and mathematical simulation of ionospheric precursors of earthquakes at midlatitudes. Geomagn. Aeron., 52, 390-397. DOI: $10.1134 / \mathrm{S} 0016793212030152$

Zolotov, O.V., Namgaladze, A.A. and Prokhorov, B.E.: 2013, Specific features of ionospheric total electron content variations in the periods of preparation of the earthquakes on March 11, 2011 (Japan) and October 23, 2011 (Turkey). Russian Journal of Physical Chemistry B, 7, No. 5, 599-605. DOI: $10.1134 / \mathrm{S} 1990793113050266$

URL-1 http://www.english.rfi.fr/europe/20111023-1000-deadearthquake-hits-east-turkey 


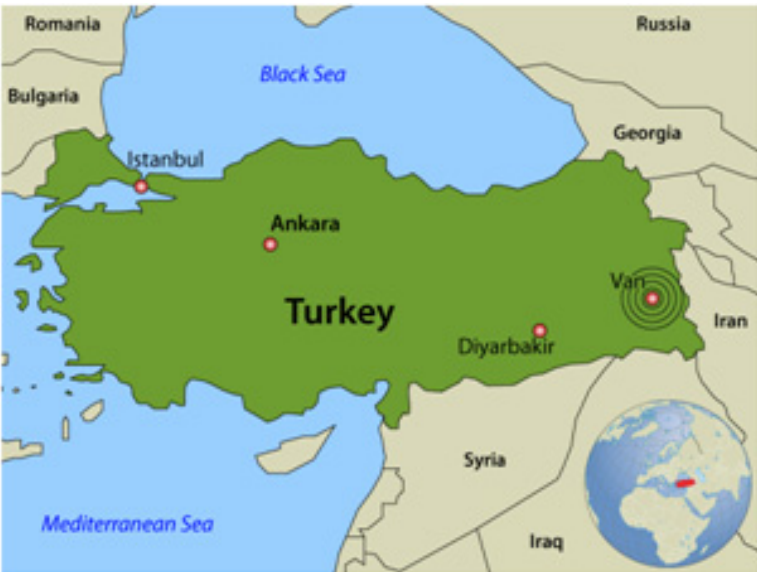

Fig. 1 Epicenter of the Van earthquake (URL-1).

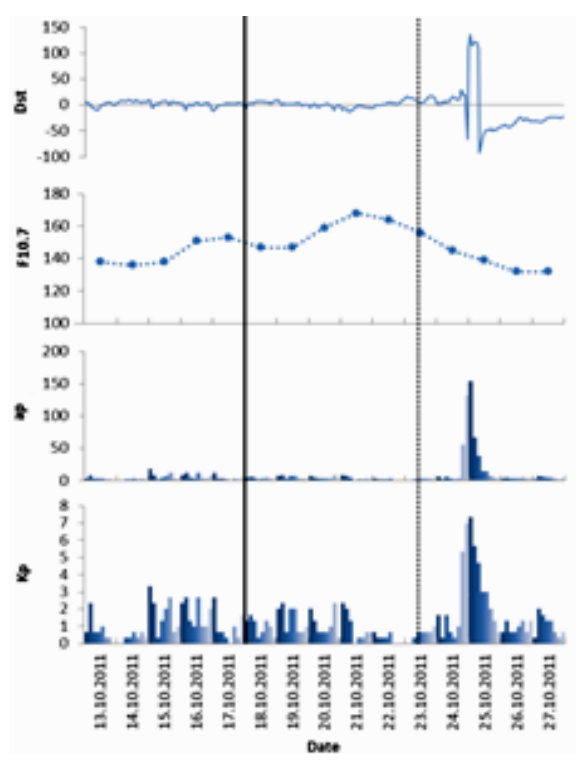

Fig. $2 \mathrm{Kp}$, ap, Dst and F10.7 index values from 13 October to 27 October (Left line indicates the beginning of the TEC precursors, right line represents the UT of the Earthquake).

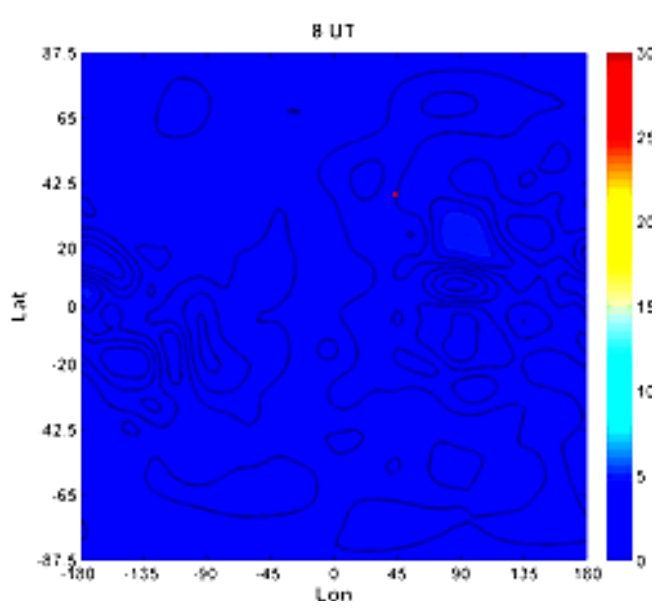

Fig. 3 Global $\triangle$ TEC map for 8:00 UT/11:00LT (20.10.2011).

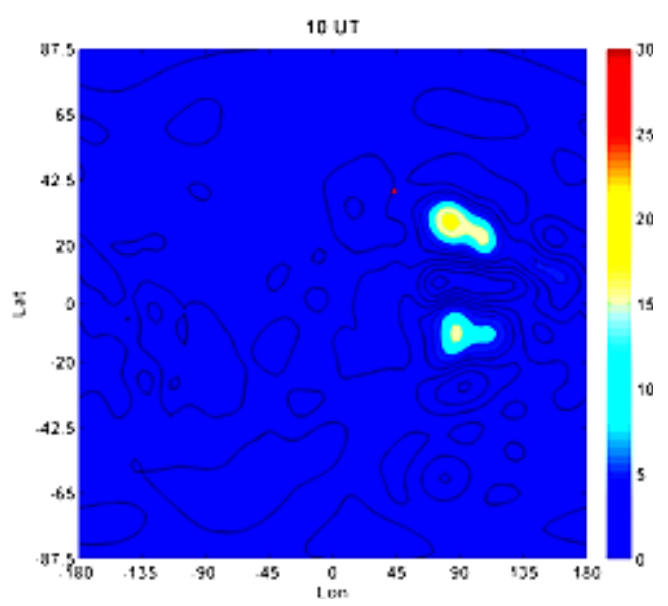

Fig. 4 Global $\triangle$ TEC map for 10:00 UT/13:00 LT (20.10.2011).

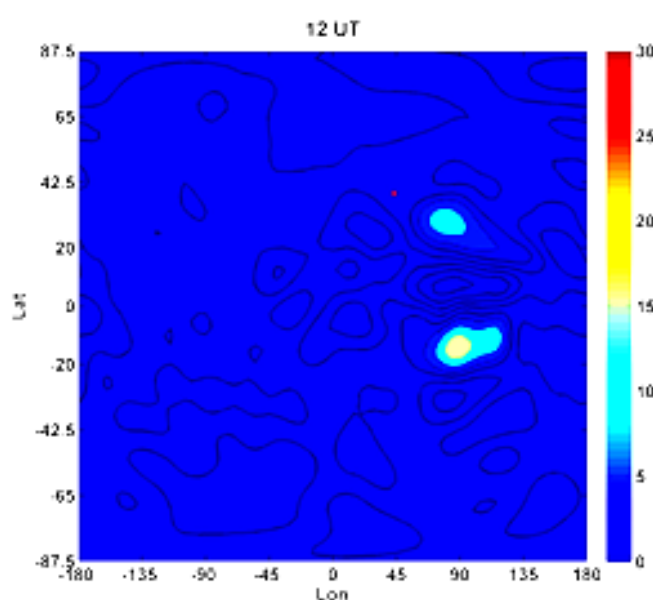

Fig. 5 Global $\triangle$ TEC map for 12:00 UT/15:00 LT (20.10.2011).

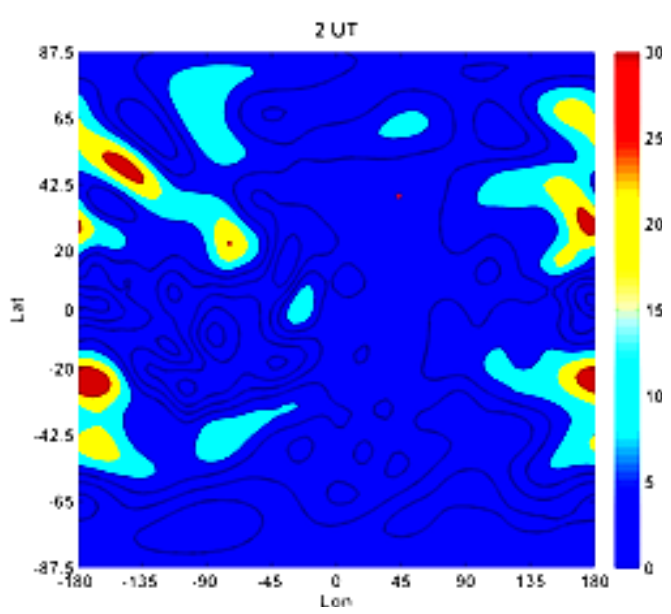

Fig. 6 Global $\triangle$ TEC map for 25.10.2011. 


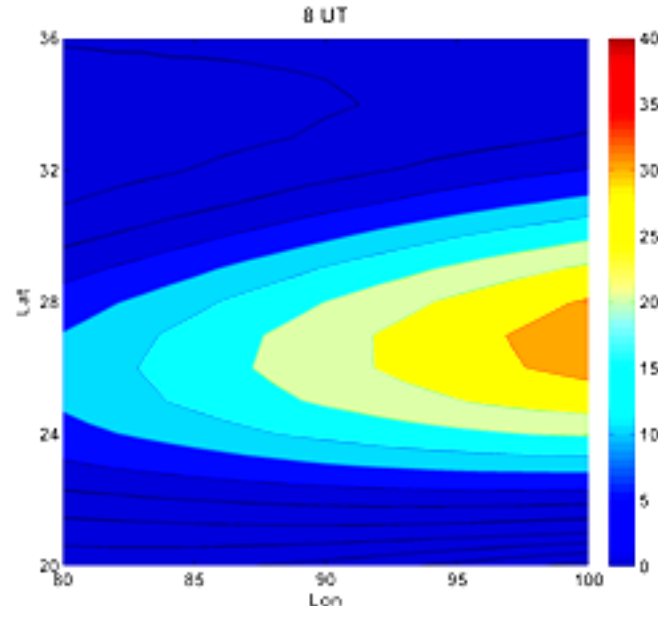

Fig. 7 PPP based $\triangle T E C$ map for 8:00 UT/11:00 LT (20.10.2011).

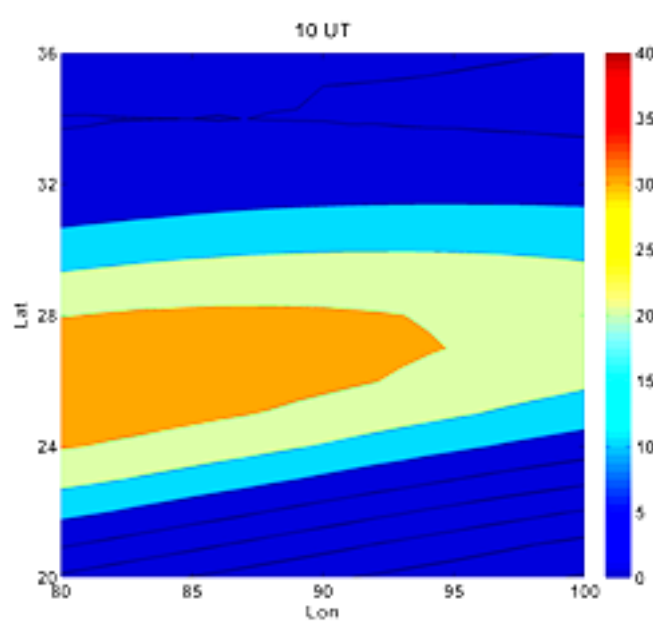

Fig. 8 PPP based $\triangle T E C$ map for 10:00 UT/13:00 LT (20.10.2011).

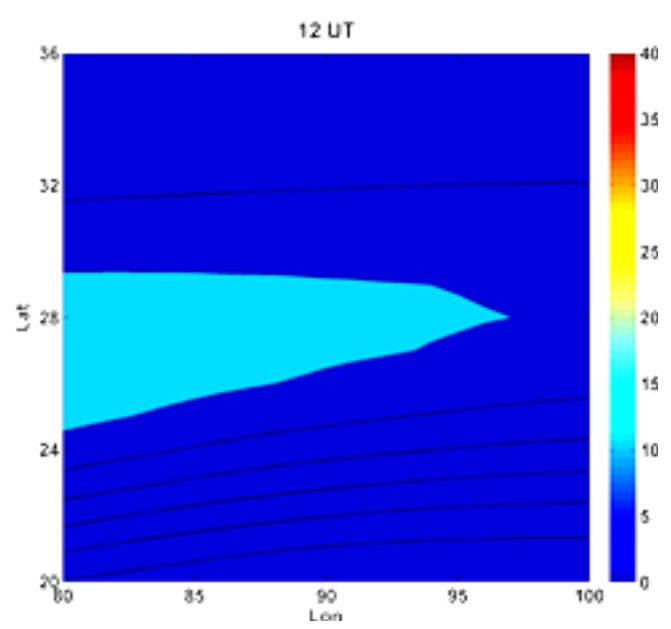

Fig. 9 PPP based $\triangle T E C$ map for 12:00 UT/15:00 LT (20.10.2011).

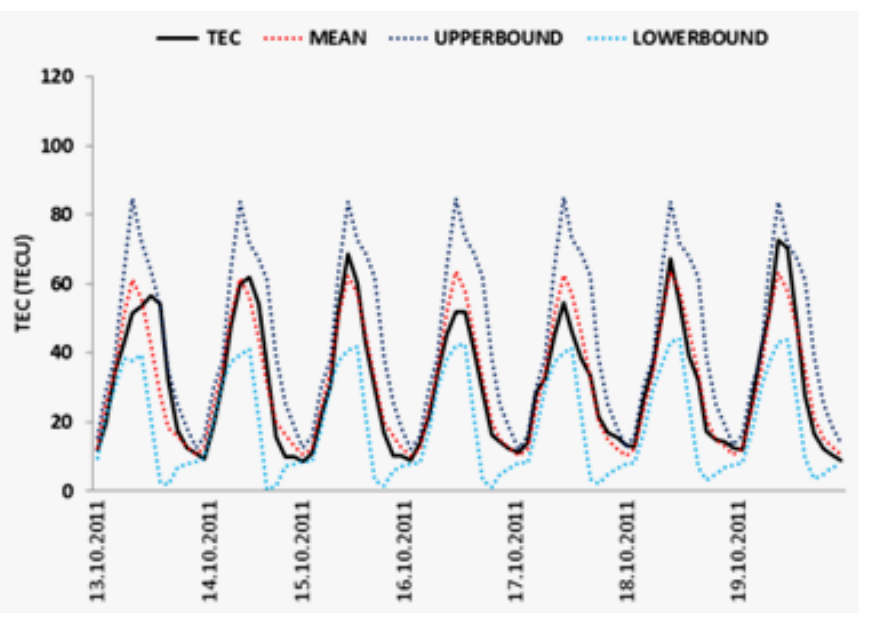

Fig. 10 Time series of observed TEC, Upper-Lower bounds and Mean values (PPP) from 13-19 October.

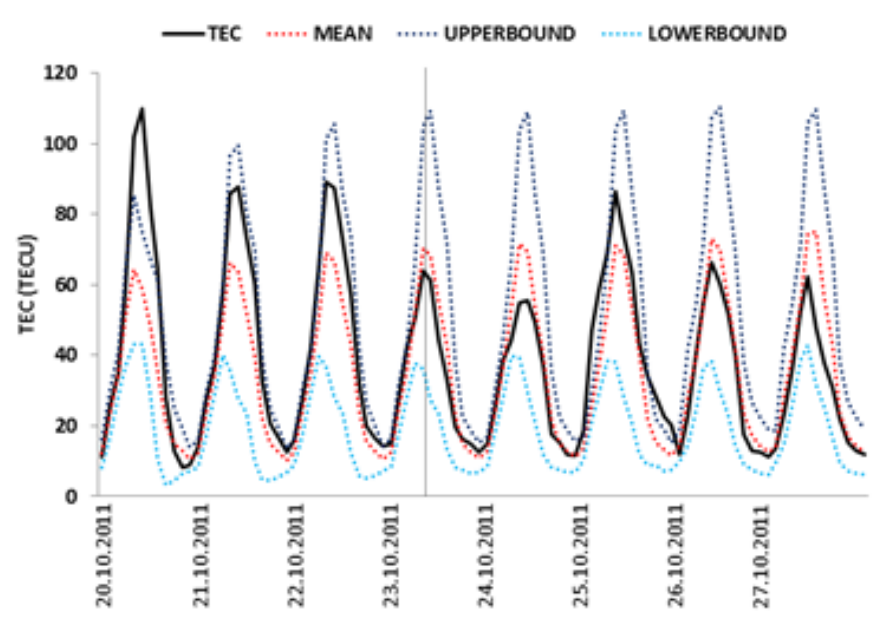

Fig. 11 Time series of observed TEC, Upper-Lower bounds and Mean values (PPP) from 20-27 October (Vertical line represents the UT of earthquake). 